\title{
Informal and formal care among persons with dementia immediately before nursing home admission
}

\author{
Arnt Egil Ydsteb $\varnothing^{1,2,3^{*}}$ (D), Jurate Šaltytė Benth ${ }^{3,4,5}$, Sverre Bergh ${ }^{3,6}$, Geir Selbæk $k^{3,6,7}$ and Corinna Vossius ${ }^{1,2}$
}

\begin{abstract}
Background: Dementia is a care intensive disease, especially in the later stages, implying in many cases a substantial carer burden. This study assesses the use of formal and informal care resources among persons with dementia during the last month before nursing home admission. It also describes main providers of informal care and assesses the extent of informal care rendered by the extended social network.
\end{abstract}

Methods: In this cross-sectional study, we collected data about persons with dementia that were newly admitted to a nursing home in Norway. Information about the amount of formal and informal care during the last 4 weeks preceding nursing home admission was collected from the primary caregivers. Clinical data were collected by examining the patients, while sociodemographic data was collected from the patients' files.

Results: A total of 395 persons with dementia were included. The amount of informal care provided by the family caregiver was $141.9 \mathrm{~h}$ per month $\mathrm{SD}=227.4$. Co-resident patients received five times more informal care than nonco-residents. Informal care from the extended social network was provided to 212 patients (53.7\%) with a mean of $5.6(S D=11.2$ ) hours per month and represented $3.8 \%$ of the total informal care rendered to the patients. Formal care was provided to $52.7 \%$ of the patients with a mean of $18.0(S D=50.1)$ hours per month. Co-residency was significantly associated with more informal care, and the associations varied with respect to age, relation to the caregiver, and the caregiver's working situation. Good/excellent general health was associated with less formal care.

Conclusion: Persons with dementia on the verge of admission to a nursing home are mainly supported by the family caregiver, and the use of informal care is particularly high among co-residents. In order to delay nursing home admission, future research should explore the unrealized care potential in extended social networks, as well as the potential for increasing the number of recipients of formal care services.

Keywords: Dementia, Informal care, Formal care, Resource use, Living situation, Social network

\footnotetext{
* Correspondence: arnt.egil.ydstebo@stavanger.kommune.no

${ }^{1}$ Centre for Age-related Medicine, Stavanger University Hospital, Stavanger, Norway

${ }^{2}$ Centre for Development of Institutional and Home Care Services Rogaland, Stavanger, Norway

Full list of author information is available at the end of the article
}

(c) The Author(s). 2020 Open Access This article is licensed under a Creative Commons Attribution 4.0 International License, which permits use, sharing, adaptation, distribution and reproduction in any medium or format, as long as you give appropriate credit to the original author(s) and the source, provide a link to the Creative Commons licence, and indicate if changes were made. The images or other third party material in this article are included in the article's Creative Commons licence, unless indicated otherwise in a credit line to the material. If material is not included in the article's Creative Commons licence and your intended use is not permitted by statutory regulation or exceeds the permitted use, you will need to obtain permission directly from the copyright holder. To view a copy of this licence, visit http://creativecommons.org/licenses/by/4.0/ The Creative Commons Public Domain Dedication waiver (http://creativecommons.org/publicdomain/zero/1.0/) applies to the data made available in this article, unless otherwise stated in a credit line to the data. 


\section{Background}

The number of people living with dementia worldwide was estimated as 35.6 million in 2010, and the numbers are expected to double over the next 20 years [1]. Strategies are needed to secure sufficient support for people living with dementia as well as their informal and professional caregivers without financially overstraining health and welfare systems. Health economic evaluations show that nursing home placement is the most significant factor driving costs in dementia care and that the interval from diagnosis to institutionalization is about $30-40$ months [2-5]. A considerable amount of informal care is provided in the patient's home, and the burden of care is one of the main important factors associated with nursing home admission (NHA) [6-11]. Several studies report that a considerable amount of informal care is provided in the home environment from 30 up to $100 \mathrm{~h}$ per week in their respective populations $[7,10,12-16]$. Factors associated with increased informal care are dementia severity, severe neuropsychiatric symptoms, and increased functional impairment $[7,8,12,17-19]$. The influence of co-residency between the primary caregiver and the person with dementia is of particular interest. Previous studies have found associations between co-residency and increased informal care, while more formal care was associated with persons with dementia living alone $[12,15,17,20]$.

Expecting an increasing number of persons with dementia, The Norwegian Ministry of Health published the first national Dementia Strategy in 2007 to better meet the needs of patients, family caregivers, and the health care system. This strategy was updated in 2015. One of the main goals of the Norwegian Dementia Strategy 2020 [21] is to enhance the support to the family caregivers and better the cooperation with voluntary services to empower persons with dementia to participate more actively in society and to live longer in their own homes. A study performed in eight European countries found that informal care from family and friends, in addition to the primary caregiver, were available to less than half of the carers in the study and suggested that provision of informal support to the carer may act as a protective factor for the perceived carer burden [14]. However, knowledge about the extent of informal care in Norway delivered during the period before NHA, and the providers of informal care, not only including primary caregivers but also the extended social network, is scarce. Better insight to the extent of care provided in patients' homes, who provides the care, and what factors are related to the amount of care in the period before NHA may assist the development of new services aiming to prolong time to nursing home admission.

The aim of this study was to assess the resource use in formal and informal care among persons with dementia during the last month before NHA, and to assess clinical and sociodemographic factors associated with the use of care. We aimed as well as to describe the main providers of informal care, and to assess the amount of informal care rendered by the extended social network.

\section{Methods \\ Setting}

This is a cross-sectional study assessing baseline data in a sample drawn from the Resource Use and Disease Course in Dementia - Nursing Home (REDIC-NH) project.

\section{Study population}

The study population was a sub-sample of participants in the- REDIC-NH project. The REDIC-NH study is a longitudinal observational study that includes newly admitted patients from 47 small and large nursing homes in four Norwegian counties and follows them from admission to the $\mathrm{NH}$ over a course of 5 years or until death [22]. Patients older than 65 years, or younger than 65 years but with established dementia, were included. In addition, the expected stay in the $\mathrm{NH}$ had to be more than 4 weeks. Patients with a life expectancy shorter than 6 weeks were not eligible. The study included a convenience sample of 695 persons, and recruitment took place between January 2012 and August 2014.

To increase homogeneity and describe the resource use in a dementia population exclusively, patients without dementia, or not permanently admitted to $\mathrm{NH}$ where excluded from the present study, as were participants without complete Resource Utilization in Dementia (RUD) questionnaire.

To be admitted to a long-term NH stay in Norway, the person must apply to the municipality. The application is evaluated based on a needs' assessment, and available places are allocated based on urgency. If there are no available places, the applicant usually is placed on a waiting list, with a waiting period from a few days up to several weeks.

\section{Ethical considerations}

The patients' capacity to consent was assessed by the nursing home staff, including a physician. Written informed consent was obtained from patients with the capacity to consent or from the family caregivers on behalf of the patients in cases of reduced capacity to consent. The study was approved by the Regional Committee for Medical and Health Research Ethics (2011/1738).

\section{Data collection}

Data were collected by healthcare workers at the nursing home, under the supervision of 10 research nurses. The research nurses completed 5 days of training prior to the start of the study, and the data collectors completed 2 days of training. Data were collected through cognitive and physical tests and structured interviews with the 
patients, their family caregivers defined as a next of kin who looked after the patient at least once a week, and the health workers.

\section{Measures}

Demographic data included the patients' age and gender and were collected by reviewing the patients' files kept at the NHs. A diagnosis of dementia according to the ICD-criteria [23] was independently established by two of the authors (SB and GS) based on all available information about the patients. Both SB and GS are specialists in psychiatry and experienced in geriatric psychiatry and research. If no consensus was reached, a third psychiatrist was consulted.

The clinical measures dementia severity and severity of physical health were obtained using the following instruments: The General Medical Health Rating (GMHR) [24], a four-category, reliable, and valid global bedside assessment tool for rating the severity of physical health. The score is based on an overall assessment by health care workers. The Clinical Dementia Rating Scale (CDR) assesses the severity of dementia as no dementia, possible dementia, and mild, moderate, or severe dementia. CDR comprises six items (memory, orientation, judgement and problem solving, community affairs, home and hobbies, and personal care). A score is calculated according to an algorithm where the memory item is given more weight. For statistical purposes, we calculated the CDR sum of boxes (CDR-SOB), which offers an extended range of values and is calculated by adding the item scores (range 0-18). Higher scores indicate more severe dementia [25].

The extent of formal care and the extent and providers of informal care during the last 4 weeks preceding NHA were recorded by the RUD questionnaire, that is answered by the primary caregiver and includes the following information about the primary caregiver [26]: Age, gender, relation to the patient, co-residential status, work status, hours worked last month, and lost work hours due to care tasks in the last month. Information about the extended social network included: Relation to patient and hours of provided informal care last month. The extent of informal care provided by the family caregiver last month was recorded in regard to the following three aspects: 1) the time used to help the patients with personal activities of daily living (PADL), 2) the time used on instrumental ADL (IADL), 3) and the time used on supervision, like helping the patient with orientation or preventing behavior that is distressing to the patient. We calculated the total informal care time by summarizing the amounts of time for these three types of care. If this sum exceeded $24 \mathrm{~h}$ per day, a total informal care time of $24 \mathrm{~h}$ per day was set. Formal care was equalled to the time provided by professional home care services, while services like home help, meal delivery, day care centres, or respite care were not included due to insufficient data.

\section{Statistical analysis}

Data are described by the means and standard deviations (SD) or frequencies and percentages. Differences between groups were assessed by Independent Samples t-test for continuous variables and the $x^{2}$-test for categorical variables. Associations between predefined covariates (gender, age, caregiver gender, caregiver relation to patient, caregiver in paid work, co-residency with family caregiver, GMHR, and $\mathrm{CDR}$ ) and the three outcome variables (informal care by the primary caregiver, informal care by the extended social network and formal care) were assessed by estimating bivariate and multiple linear mixed models. Random effects for nursing homes were included in the models to adjust the estimates for possible within-nursing-home correlations. Stratification by living with or without a caregiver was performed by including interactions between the dichotomous variable (co-residency with or without caregiver) and all covariates. Interactions with $p<0.1$ were kept in the model. Missing values in variables co-resident, carer relation, and carer in work were imputed by logical rules whenever possible. The analyses were performed using IBM SPSS Statistics for Windows version 25.0 (Armonk, NY: IBM Corp.) and SAS v 9.4. Results with $p$-values less than 0.05 were considered statistically significant.

\section{Results \\ Study population}

The REDIC-NH cohort consists of 696 patients, among which 445 had dementia and were permanently admitted to a nursing home. However, 50 patients had to be excluded due to missing or incomplete RUD questionnaires. Thus, the study included 395 patients with a mean age of 84.4 $(\mathrm{SD}=7.5)$ years, and $265(67.1 \%)$ patients were female. According to the CDR, 277 (73.9\%) had moderate or severe dementia. There were no differences regarding demographic or clinical characteristics between patients who completed the RUD questionnaire and those who did not.

The extent of formal and informal care is presented in Table 1.

\section{The extent of informal care}

The mean care time provided by the family caregiver was $141.9(\mathrm{SD}=227.4)$ hours per month, while the total contribution of the patients' extended social network, including family members, was $5.6(\mathrm{SD}=11.2)$ hours per month.

\section{The extent of formal care}

Formal care was provided to 208 (52.7\%) of the patients with a mean of $34.2(\mathrm{SD}=64.9)$ hours per month among 
Table 1 Formal and informal care during the last month before NHA $(N=395)$

\begin{tabular}{|c|c|}
\hline Variable & \\
\hline \multicolumn{2}{|l|}{ Formal care } \\
\hline Recipients, n (\%) & $208(52.7)$ \\
\hline Mean hours of formal care, recipients of formal care, last month (SD) & $34.2(64.9)$ \\
\hline Mean hours of formal care, whole sample last month (SD) & $18.0(50.1)$ \\
\hline \multicolumn{2}{|l|}{ Informal care by the primary carer, mean hours last month (SD) } \\
\hline PADL & $74.8(170.5)$ \\
\hline IADL & $65.9(142.1)$ \\
\hline Supervision & $55.9(158.9)$ \\
\hline Total informal care by the primary carer & $141.9(227.4)$ \\
\hline \multicolumn{2}{|l|}{ Informal care by wider social network, mean hours last month (SD) } \\
\hline Family & $3.8(10.2)$ \\
\hline Relatives & $0.4(3.0)$ \\
\hline Friends & $0.1(0.8)$ \\
\hline Neighbours & $0.2(1.0)$ \\
\hline Others & $0.9(4.0)$ \\
\hline Total informal care by the extended social network & $5.6(11.2)$ \\
\hline
\end{tabular}

NHA Nursing Home Admission, SD Standard Deviation

those receiving formal care. For the whole sample, the mean amount of formal care per month was 18.0 (SD = 50.1) hours.

\section{Informal care - characteristics of the family caregiver}

Characteristics of the family caregivers and the extended social networks are presented in Table 2. Of the 395 patients, 379 (95.9\%) had a family caregiver, of whom 228 (60.2\%) were females, 255 (67.3\%) were the patients' children, while $81(21.4 \%)$ were spouses. The mean age was 57.4 ( $\mathrm{SD}=8.9)$ years for family caregivers who were the patients' children and 77.7 ( $\mathrm{SD}=7.6$ ) years for family caregivers who were the patients' spouses. Co-resident caregivers accounted for 105 (26.6\%) of the sample. A total of 194 (54.2\%) caregivers were doing paid work, and they worked 34.9 ( $\mathrm{SD}=10.3$ ) hours per week. Of the caregivers in paid work, $60(30.8 \%)$ reported a mean loss of 11.2 $(\mathrm{SD}=9.6)$ working hours per week due to care tasks.

\section{Informal care - characteristics of the extended social network}

In our study sample, 212 (53.7\%) patients received support from at least one member of their social network, whereas 183 (46.3\%) had no additional carers beside the family caregiver. Of the 212 patients that received help from their extended social network, 154 (72.6\%) received help from family members, while 29 (13.7\%) received help from more distant relatives, 15 (7.1\%) received help from friends, $22(10.4 \%)$ received help from neighbours, and $44(20.8 \%)$ received help from others (Table 2 ).

\section{The impact of sociodemographic and clinical factors on} the use of care

Male patients received more informal care than female patients (187.1 versus $120.3 \mathrm{~h}$ per month, $p=0.016)$. There was no statistical difference between genders regarding formal care. Co-resident patients received more informal care (343.1 versus $67.4 \mathrm{~h}$ per month, $p<0.001$ ) and less formal care than patients living alone (9.1 versus $21.2 \mathrm{~h}$ per month, $p=0.001$ ), while there was no statistical difference in the extent of informal care by the extended social network between co-residents and nonco-residents (Fig. 1). The ratios of informal to formal care were 37.7:1 for co-resident patients and 3.2:1 for patients living alone. Family caregivers who did paid work provided less informal care than those who were not working ( 74.2 versus $228.7 \mathrm{~h}$ per month, $\mathrm{p}<0.001)$. There were no statistical differences in formal care between patients with working and non-working family caregivers.

According to the bivariate linear mixed models presented in Table 3, more hours of informal care by the family caregiver was significantly associated with the patient being of lower age, having male gender, having a family caregiver not doing paid work, having a spouse as a family caregiver as opposed to a child, having more severe dementia, and having a co-resident caregiver. Having a family caregiver doing paid work was associated with more informal care from the social network. Having a spouse as the family caregiver as opposed to a child, good/excellent GMHR, and co-residency were associated with less formal care. 
Table 2 Description of the family caregivers $(n=379)$ and the patient's extended social network

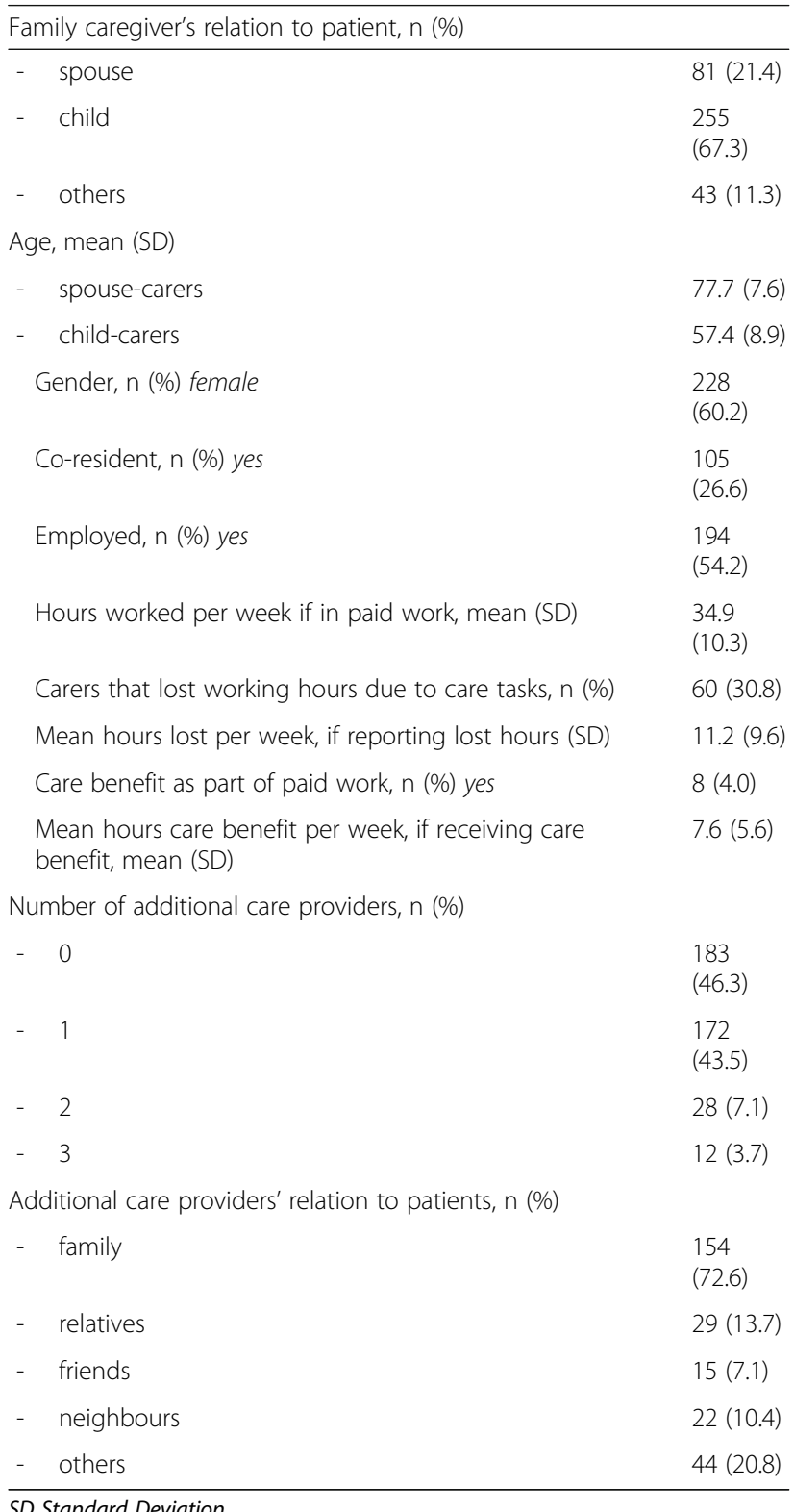

SD Standard Deviation

In the multiple model, female gender of caregiver was significantly associated with more hours of informal care by the family caregiver. Several interactions with coresidency were present in the model. Co-resident patients had significantly more hours of informal care than non-co-resident patients with differences varying between strata. There were no differences between male and female patients. Differences in provided informal care between spouses and children caregivers were significantly larger among non-co-resident patients than co-resident patients, Differences in received informal care from working and non-working caregivers were significantly higher among co-resident patients than non- co-resident patients. Higher age was associated with fewer hours of informal care, and there was a significantly stronger reduction among co-resident patients than non-co-resident patients. Less formal care was only associated with good/excellent GMHR.

\section{Discussion}

This study assessed the use of formal and informal care among home-dwelling persons with dementia during the last month before permanent admission to a nursing home. For the two-thirds of the patients living alone, their closest caregiver was mainly one of their children, while for the patients living in co-residency, the caregiver was most frequently the spouse. Half of the sample received formal care in the form of home care services. The extent of informal care was substantially larger than the extent of formal care, and the majority of the informal care was delivered by the family caregiver, while the extended social network only contributed $3.8 \%$. Half of the primary caregivers even reported to have no additional help at all, including the majority of spouses living with the patient. Only a small portion of $10 \%$ received care from two or more persons in their extended social network; however, the low hourly contribution suggests that the help was somewhat sporadic.

Care contributions from the extended social network have seldom been investigated or discussed in previous studies. In the US, The National Study of Caregiving found that $73-78 \%$ of caregivers to persons with dementia had additional helpers [27]. In Norway, the REDIC project found that 50 to $70 \%$ of caregivers had additional helpers, however, our findings show that the hourly contribution was low. We can only suggest possible reasons for the low contribution. Norway has high employment rates among both genders, possibly reducing the opportunity to support relatives [28]. Another explanation could be the increasing urbanization causing longer geographical distance between relatives [29]. The massive expansion of the public care services during the last 50 years might also lead to a perception that the provision of care to elderly relatives is a state- rather than a family-responsibility [30]. As more then $95 \%$ of all informal care was rendered by the main caregiver, there seems to exist unexhausted resources in involving the extended social network in order to relief the burden experienced by primary caregivers. However, the research community has yet to explore how to access these resources and the barriers that might exist in both rendering care but as well accepting it.

We found that the family caregiver provided a mean of $142 \mathrm{~h}$ per month of informal care. In contrast, a health economic analysis performed on several cohorts of persons with dementia concluded that a mean of 60 to $85 \mathrm{~h}$ per months of informal help were rendered at 


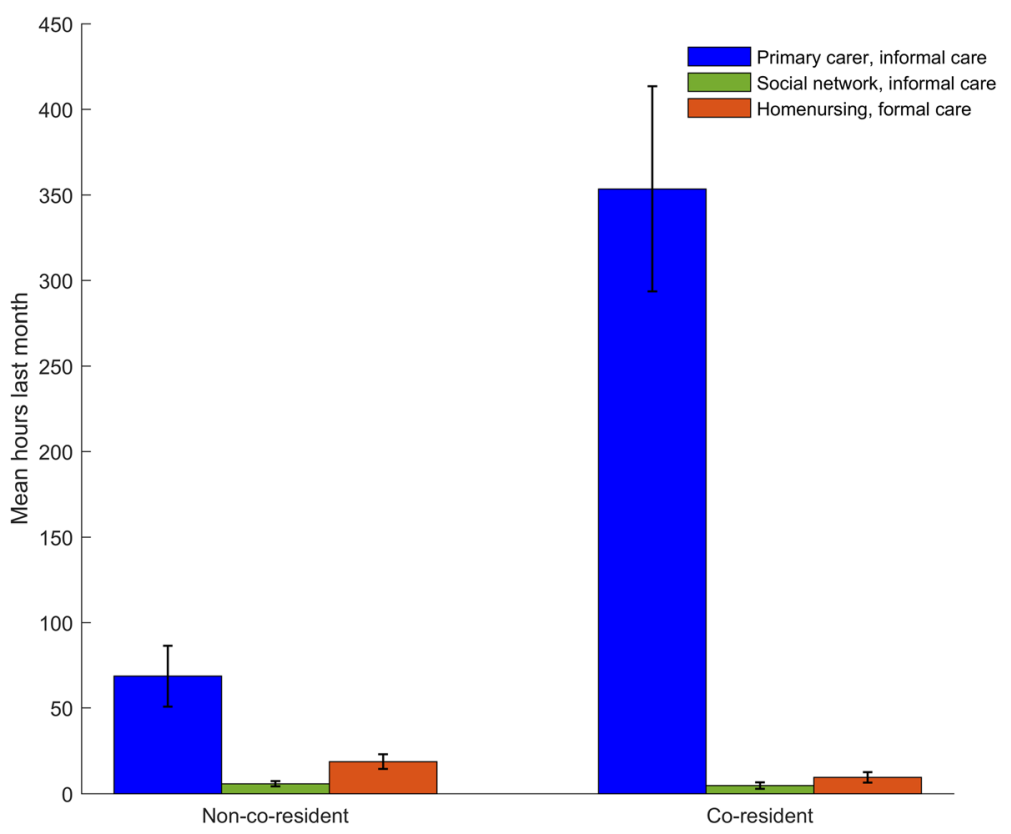

Fig. 1 Time used to care for patients during the last month before nursing home admission

the point of diagnosis, thus, indicating a considerable increase in the need for care in the period leading up to NHA [31]. A previous study conducted in eight European countries with a cohort similar to the REDIC cohort reported $360 \mathrm{~h}$ of informal care per month, while studies observing cohorts with younger patients in earlier stages of dementia reported a range of 82 to $160 \mathrm{~h}$ per month [12, 14-16]. These differences might be owed to varying shares of co-residing family caregivers. In addition, cultural differences regarding the experienced obligation to care for elder family members as well as the accessibility and costs of formal care might impact the extent of informal care.

Co-residency was a main predictor for the extent of informal care rendered. This might be an indication of "supply creates its own demand", as co-resident caregivers (the spouse in most cases) might be more involved than needed when assisting the patients with daily tasks and supervision [32]. It could as well lead to an overestimation of care time, as it might be difficult to distinguish shared household activities from care activities. On the other hand, more severe dementia was associated with more informal care, suggesting that the amount of informal care is adjusted to the severity of dementia.

Only about half of the sample received formal care and our finding of $4.5 \mathrm{~h}$ of formal care per week is considerably lower than the findings in a comparable study that reported $7.5 \mathrm{~h}$ [15]. Another analysis of care resources to Norwegian home-dwelling persons with and without dementia found that $3.2 \mathrm{~h}$ of formal care was provided to a sub-population with dementia [31]. Thus, indicating a progressive increase in formal care provision. In recent years Norwegian Dementia Strategies have asked for more differentiated care services and a more individualized approach toward persons with dementia and their family caregivers. Consequently, we would expect a higher amount of informal care time and dementia-specific clinical measures to be associated with the extent of formal care, but we found that only somatic health was related to it. A possible explanation could be that Norwegian home care services mainly cover help with tasks related to ADL dependencies and, to a lesser degree, with tasks related to IADL dependencies and supervision of the patients [33].

Our finding that co-resident patients received less formal care and more informal care than patients living alone is consistent with previous studies [12, 15-17]. It indicates a substitutive rather than complimentary relationship between formal and informal care use and are in line with a recently published study in six WesternEuropean countries [34]. This might as well apply to the contributions from the extended social network as more support was provided from the extended social network in cases with non-co-residency and when the primary carer was holding a job.

The low use of formal care substituted by a high use of informal care might be due to a lack of perceived capacity or skill in the primary care services to offer specialized and individualized dementia care, especially care and support directed towards co-resident caregivers. A cross-European study found that the formal services available to persons with dementia were non-specific and not tailored to the patient group or the specific 
Table 3 Bivariate and multiple models of formal and informal care

\begin{tabular}{|c|c|c|c|c|c|c|}
\hline \multirow[t]{3}{*}{ Independent variables } & \multicolumn{6}{|l|}{ Dependent variables } \\
\hline & \multicolumn{2}{|c|}{ Informal care by primary carer $(N=344)$} & \multicolumn{2}{|c|}{ Informal care, social network $(N=316)$} & \multicolumn{2}{|l|}{ Formal care $(N=356)$} \\
\hline & $\begin{array}{l}\text { Regr.coeff. } \\
\text { (95\% Cl / SE) }\end{array}$ & $p$-value & Regr.coeff. (95\% Cl) & $p$-value & $\begin{array}{l}\text { Regr.coeff. } \\
(95 \% \mathrm{Cl})\end{array}$ & $p$-value \\
\hline \multicolumn{7}{|l|}{ BIVARIATE MODELS } \\
\hline Gender, male & $76.9(25.6 ; 128.2)$ & 0.003 & $1.1(-1.6 ; 3.9)$ & 0.428 & $1.4(-6.8 ; 9.6)$ & 0.738 \\
\hline Age & $-6.9(-10.1 ;-3.8)$ & $<0.001$ & $-0.1(-0.3 ; 0.0)$ & 0.120 & $0.1(-0.5 ; 0.6)$ & 0.841 \\
\hline Carer gender, male & $-21.5(-71.1 ; 28.2)$ & 0.396 & $-0.1(-2.7 ; 2.5)$ & 0.925 & $-0.36(-8.20 ; 7.5)$ & 0.929 \\
\hline \multicolumn{7}{|l|}{ Carer relation } \\
\hline Spouse & $302.4(250.8 ; 353.9)$ & $<0.001$ & $-3.0(-6.1 ; 0.2)$ & 0.062 & $-9.7(-19.3 ;-0.1)$ & 0.047 \\
\hline Children & 0 & & 0 & & 0 & \\
\hline Others & $41.2(-25.7 ; 108.1)$ & 0.227 & $-2.6(-7.0 ; 1.7)$ & 0.235 & $3.7(-8.5 ; 16.0)$ & 0.549 \\
\hline Carer in work, yes & $-155.6(-201.6 ;-109.6)$ & $<0.001$ & $3.7(1.1 ; 6.2)$ & 0.005 & $4.7(-3.0 ; 12.4)$ & 0.230 \\
\hline GMHR, poor/fair & $6.1(-42.5 ; 54.8)$ & 0.804 & $-0.9(-3.5 ; 1.7)$ & 0.480 & $8.8(1.2 ; 16.4)$ & 0.024 \\
\hline CDR-SB & $8.5(1.5 ; 15.6)$ & 0.017 & $0.2(-0.2 ; 0.5)$ & 0.433 & $-0.2(-1.3 ; 0.9)$ & 0.699 \\
\hline Co-resident & $275.6(229.8 ; 321.4)$ & $<0.001$ & $-1.1(-3.9 ; 1.8)$ & 0.453 & $-11.6(-20.1 ;-3.1)$ & 0.008 \\
\hline \multicolumn{7}{|l|}{ MULTIPLE MODELS } \\
\hline Gender, male & $21.5(26.6)$ & 0.419 & $1.8(-1.1 ; 4.8)$ & 0.217 & $2.6(-6.1 ; 11.2)$ & 0.565 \\
\hline Age & $-2.0(1.7)$ & 0.229 & $-0.2(-0.4 ; 0.03)$ & 0.094 & $-0.1(-0.6 ; 0.5)$ & 0.790 \\
\hline Carer gender, male & $-45.0(-89.0 ;-1.0)$ & 0.045 & $0.5(-2.2 ; 3.1)$ & 0.743 & $1.2(-6.9 ; 9.19)$ & 0.774 \\
\hline \multicolumn{7}{|l|}{ Carer relation } \\
\hline Spouse & $298.8(74.5)$ & $<0.001$ & $-4.5(-9.8 ; 0.75)$ & 0.093 & $-1.9(-17.6 ; 13.9)$ & 0.813 \\
\hline Children & 0 & & 0 & & 0 & \\
\hline Others & $10.6(35.1)$ & 0.763 & $-1.9(-6.3 ; 2.6)$ & 0.411 & $3.8(-8.8 ; 16.5)$ & 0.551 \\
\hline Carer in work, yes & $-29.3(26.7)$ & 0.273 & $2.5(-0.6 ; 5.6)$ & 0.110 & $1.3(-8.0 ; 10.47)$ & 0.790 \\
\hline GMHR, poor/fair & $14.1(-25.2 ; 53.5)$ & 0.481 & $-0.9(-3.4 ; 1.7)$ & 0.518 & $8.5(0.8 ; 16.2)$ & 0.030 \\
\hline CDR-SB & $-0.3(-6.1 ; 5.5)$ & 0.921 & $0.2(-0.2 ; 0.5)$ & 0.411 & $0.03(-1.1 ; 1.2)$ & 0.964 \\
\hline Co-resident & $1077.4(314.7)$ & 0.001 & $1.81(-2.3 ; 5.9)$ & 0.383 & $-10.0(-22.3 ; 2.3)$ & 0.110 \\
\hline Gender x Co-resident & $95.09(52.70)$ & 0.072 & & & & \\
\hline Age $\times$ Co-resident & $-8.74(3.34)$ & 0.009 & & & & \\
\hline \multicolumn{7}{|c|}{ Carer relation $\times$ Co-resident } \\
\hline Spouse & $-321.03(98.72)$ & 0.001 & & & & \\
\hline 1 Children & 0 & & & & & \\
\hline Others & $127.97(107.31)$ & 0.234 & & & & \\
\hline Carer in work $\mathrm{x}$ & $-154.95(66.30)$ & 0.020 & & & & \\
\hline Co-resident & & & & & & \\
\hline
\end{tabular}

Cl Confidence Interval, SE Standard Error, GMHR General Medical Health Rate, CDR-SB Clinical Dementia Rating Sum of Boxes

individual's needs [35]. Other identified barriers to the use of formal care are that the family caregivers do not consider the need for the care, them or the patient having negative attitudes and beliefs towards formal care, low awareness of services available, poor accessibility to services, or high costs [36-38]. Another possible barrier to formal care derives from a Canadian study were case managers seemed to purposely exhaust family resources before making formal home care services available [39]. Increasing the number of recipients of formal care or increasing the hours of care delivered to the respective recipients might contribute to relief the burden of primary caregivers and thus to delay NHA $[5,40]$.

\section{Limitations and strengths}

The strengths of this study include a large sample of nearly 400 persons with dementia who were assessed for informal and formal care used during the last month before NHA. Standardized interviews were carried out by adequately trained and supervised healthcare workers, 
thus securing high-quality data. Private entities rarely provide health care service in the municipalities in Norway. Thus, the municipalities are almost exclusively responsible for the provision of care services and provide a homogenous environment for health service research with similar criteria for NHA.

A major limitation is that our sample might not be representative of the general population of persons with dementia in this stage in Norway as only patients that completed the BL examination were included, and the mean time from admission to BL was 10.5 weeks [22]. As a confounding factor we might thus have excluded patients who were eligible for the study but who died shortly after admission to a nursing home, or eligible persons that did not have a family caregiver. Furthermore, the physical and cognitive tests were first performed at the BL examination and could be sensitive to changes during this time period or due to the event of admission. However, the GMHR and CDR have shown to be stable over time [41-43]. Moreover, caregiver-reported data from the RUD questionnaire may have yielded inaccuracies in the extent of formal and informal care.

We equated formal care with home care services without taking into account other forms of services, such as meal delivery, day care centres, or respite care due to insufficient or lacking data. This might have resulted in an underestimation of the extent of formal care. However, we consider home care services as the most relevant type of formal care in Norway, and as well when comparing different health care systems.

This study was performed in Norway, and the findings might not be transferrable to other countries with different health systems. In Scandinavia, public health services provide the majority of care, and it is rendered free of charge for relatively small fees to the patients. Thus, the extent of formal care, the point of time for NHA and the extent of informal care might differ substantially in other health care systems and cultural settings.

\section{Conclusion}

We found that persons with dementia on the verge of admission to a nursing home are mostly supported by informal care provided by one primary carer, while the amount of care provided by the patients' extended social network and the provision of formal care was low. Future research should explore the unrealized care potential in the extended social networks and the possibilities in more diverse formal care services directed to persons with dementia and their caregivers.

\section{Abbreviations}

NHA: Nursing home admission; REDIC-NH: Resource Use and Disease Course in Dementia-Nursing Home; RUD: Resource utilization in dementia; P-

ADL: Personal activity of daily living; IADL: Instrumental activity of daily living; GMHR: General medical health rating; CDR: Clinical dementia rating;

SD: Standard deviation

\section{Acknowledgements}

Our gratitude goes to the six collaborating research centres that developed the REDIC project: the Centre for Age-related Functional decline and Disease, Innlandet Hospital Trust (leader of the project); Dept. of Health Management and Health Economics, University of Oslo; South-Eastern Norway Regional Health Authority's Health Services Research Centre, Akershus University Hospital; Centre for Elderly and Nursing Home Medicine (SEFAS); Department of Global Public Health and Primary Care; Faculty of Medicine and Dentistry, University of Bergen; and The Regional Centre for Elderly Medicine and Cooperation (SESAM), Stavanger University Hospital. We would also like to thank the managers and the staff at the nursing homes in Hedmark, Oppland, Hordaland, and Nord-Trøndelag that took part in the study, and the patients and their family caregivers for giving us their information.

\section{Authors' contributions}

$\mathrm{CV}, \mathrm{GS}, \mathrm{SB}, \mathrm{JSB}$, and AEY developed the concept, study design and research questions. $\mathrm{AEY}$ and $\mathrm{CV}$ processed the data, performed descriptive analysis and prepared the manuscript. JSB, SB, and GS critically reviewed and added comments to the manuscript at all phases. JSB provided expert advice on the statistical analysis and performed the bivariate and multiple linear mixed models. All authors took part in revising the paper and approved the final version.

\section{Funding}

The data collection was administrated by the Research Centre for Agerelated Functional decline and Disease, Innlandet Hospital Trust, and was initiated by the Norwegian Health Directorate, which also provided funding. The funding body had no role in decisions regarding the design, analysis or interpretation of the present study.

\section{Availability of data and materials}

The datasets generated and/or analysed during the current study are available for researchers in cooperation with the data owner, the Research Centre for Age-related Functional decline and Disease - Innlandet Hospital Trust. Information is available on the following page link: https://sykehusetinnlandet.no/avdelinger/alderspsykiatrisk-forskningssenter

\section{Ethics approval and consent to participate}

The patients' capacity to consent was assessed by the nursing home staff, including a physician. Written informed consent was obtained from patients with the capacity to consent or from the legal guardians on behalf of the patients in cases of reduced capacity to consent. The study with reference number 2011/1738 was approved by the Regional Committee for Medical and Health Research Ethics South-east Norway, University of Oslo.

\section{Consent for publication}

Not applicable.

\section{Competing interests}

The authors declare that they have no competing interests.

\section{Author details}

${ }^{1}$ Centre for Age-related Medicine, Stavanger University Hospital, Stavanger, Norway. ${ }^{2}$ Centre for Development of Institutional and Home Care Services Rogaland, Stavanger, Norway. ${ }^{3}$ Research centre for Age-related Functional decline and Disease, Innlandet Hospital Trust, Postboks 68, N-2312 Ottestad, Norway. ${ }^{4}$ Institute of Clinical Medicine, University of Oslo, Oslo, Norway. ${ }^{5}$ Health Services Research Unit, Akershus University Hospital, Akershus,

Norway. ${ }^{6}$ Norwegian National Advisory Unit on Ageing and Health, Vestfold Hospital Trust, Tønsberg, Norway. ${ }^{7}$ Institute of Health and Society, University of Oslo, Oslo, Norway.

Received: 14 November 2019 Accepted: 12 August 2020

Published online: 18 August 2020

References

1. Prince M, Bryce R, Albanese E, Wimo A, Ribeiro W, Ferri CP. The global prevalence of dementia: a systematic review and metaanalysis. Alzheimers Demen. 2013;9(1):63-75.e62.

2. Andersen CK, Lauridsen J, Andersen K, Kragh-Sorensen P. Cost of dementia: impact of disease progression estimated in longitudinal data. Scand J Public Health. 2003;31(2):119-25. 
3. Wimo A, Ljunggren G, Winblad B. Costs of dementia and dementia care: a review. Int J Geriatr Psychiatr. 1997;12(8):841-56.

4. Vossius C, Rongve A, Testad I, Wimo A, Aarsland D. The use and costs of formal care in newly diagnosed dementia: a three-year prospective followup study. Am J Geriatr Psychiatr. 2014;22(4):381-8.

5. Vossius C, Selbaek G, Ydstebo AE, Benth JS, Godager G, Luraas H, Bergh S. Ressursbruk og sykdomsforløp ved demens [Resource Use and Disease Course in Dementia]. In: Alderspsykiatrisk forskningssenter, Sykehuset Innlandet; 2015.

6. Gaugler JE, Yu F, Krichbaum K, Wyman JF. Predictors of nursing home admission for persons with dementia. Med Care. 2009;47(2):191-8.

7. Rice DP, Fox PJ, Max W, Webber PA, Lindeman DA, Hauck WW, Segura E. The economic burden of Alzheimer's disease care. Health Aff (Project Hope). 1993;12(2):164-76.

8. Rongve A, Vossius C, Nore S, Testad I, Aarsland D. Time until nursing home admission in people with mild dementia: comparison of dementia with Lewy bodies and Alzheimer's dementia. Int J Geriatr Psychiatr. 2014;29(4):392-8.

9. Wergeland JN, Selbaek G, Bergh S, Soederhamn U, Kirkevold O. Predictors for nursing home admission and death among community-dwelling people 70 years and older who receive domiciliary care. Dement Geriatr Cogn Dis Extra. 2015:5(3):320-9.

10. Wimo A, von Strauss E, Nordberg G, Sassi F, Johansson L. Time spent on informal and formal care giving for persons with dementia in Sweden. Health Policy (Amsterdam, Netherlands). 2002;61(3):255-68.

11. Luppa M, Luck T, Brahler E, Konig HH, Riedel-Heller SG. Prediction of institutionalisation in dementia. A systematic review. Dement Geriatr Cogn Disord. 2008;26(1):65-78.

12. Zhu CW, Torgan R, Scarmeas N, Albert M, Brandt J, Blacker D, Sano M, Stern $Y$. Home health and informal care utilization and costs over time in Alzheimer's disease. Home Health Care Serv Q. 2008;27(1):1-20.

13. Jakobsen M, Poulsen PB, Reiche T, Nissen NP, Gundgaard J. Costs of informal care for people suffering from dementia: evidence from a danish survey. Dement Geriatr Cogn Dis Extra. 2011;1(1):418-28.

14. Sutcliffe C, Giebel C, Bleijlevens M, Lethin C, Stolt M, Saks K, Soto ME, Meyer G, Zabalegui A, Chester H, et al. Caring for a Person With Dementia on the Margins of Long-Term Care: A Perspective on Burden From 8 European Countries. J Am Med Dir Assoc. 2017;18(11):967-973.e961.

15. Gerves C, Chauvin P, Bellanger MM. Evaluation of full costs of care for patients with Alzheimer's disease in France: the predominant role of informal care. Health Policy (Amsterdam, Netherlands). 2014;116(1):114-22.

16. Michalowsky B, Flessa S, Eichler T, Hertel J, Dreier A, Zwingmann I, Wucherer $D$, Rau H, Thyrian JR, Hoffmann W. Healthcare utilization and costs in primary care patients with dementia: baseline results of the DelpHi-trial. Eur J Health Econ. 2017;19:87-102.

17. Michalowsky B, Thyrian JR, Eichler T, Hertel J, Wucherer D, Flessa S, Hoffmann W. Economic analysis of formal care, informal care, and productivity losses in primary care patients who screened positive for dementia in Germany. J Alzheimers Dis. 2015;50(1):47-59.

18. Pena-Longobardo LM, Oliva-Moreno J. Economic valuation and determinants of informal care to people with Alzheimer's disease. Eur J Health Econ. 2015;16(5):507-15.

19. Jonsson $L$, Eriksdotter Jonhagen $M$, Kilander $L$, Soininen $H$, Hallikainen $M$, Waldemar G, Nygaard H, Andreasen N, Winblad B, Wimo A. Determinants of costs of care for patients with Alzheimer's disease. Int J Geriatr Psychiatr. 2006;21(5):449-59.

20. Schneider J, Hallam A, Murray J, Foley B, Atkin L, Banerjee S, Islam MK, Mann A. Formal and informal care for people with dementia: factors associated with service receipt. Aging Ment Health. 2002;6(3):255-65.

21. Services $\mathrm{NMoHaC}$. Dementia Plan 2020 - A More Dementia-friendly Society. In: Edited by Helath Do: Ministry of Health and Care Services; 2017.

22. Roen I, Selbaek G, Kirkevold O, Engedal K, Testad I, Bergh S. Resourse use and disease Couse in dementia - nursing home (REDIC-NH), a longitudinal cohort study; design and patient characteristics at admission to Norwegian nursing homes. BMC Health Serv Res. 2017:17(1):365.

23. World Health Organization. The ICD-10 classification of mental and Behavioural disorders in: Clinical descriptions and diagnostic guidelines. Geneva: World Health Organization; 1992.

24. Lyketsos CG, Galik E, Steele C, Steinberg M, Rosenblatt A, Warren A Sheppard JM, Baker A, Brandt J. The general medical health rating: a bedside global rating of medical comorbidity in patients with dementia. JAmGeriatrSoc. 1999;47(4):487-91.
25. O'Bryant SE, Waring SC, Cullum CM, Hall J, Lacritz L, Massman PJ, Lupo PJ, Reisch JS, Doody R. Staging dementia using clinical dementia rating scale sum of boxes scores: a Texas Alzheimer's research consortium study. Arch Neurol. 2008;65(8):1091-5.

26. Wimo A, Jonsson L, Zbrozek A. The resource utilization in dementia (RUD) instrument is valid for assessing informal care time in community-living patients with dementia. J Nutr Health Aging. 2010;14(8):685-90.

27. Riffin C, Van Ness PH, Wolff JL, Fried T. Family and other unpaid caregivers and older adults with and without dementia and disability. J Am Geriatr Soc. 2017;65(8):1821-8.

28. Statistics Norway. Labour Force survey. Oslo: Population aged 15-74, by labour force status and sex. 2019. https://www.ssb.no/en/arbeid-og-lonn/ statistikker/aku/kvartal. Accessed 17 Aug 2020.

29. Haug M. Lågare folketal i 201 Kommunar [lower population in 201 municipalities]. In: Statistics Norway; 2019.

30. Ministry of Health and Care Services. Meld. St. 29 Morgendagens omsorg. Bergen. Norway. 2013. https://www.regjeringen.no/contentassets/34c8183 cc5cd43e2bd341e34e326dbd8/no/pdfs/stm201220130029000dddpdfs.pdf. Accessed 17 Aug 2020.

31. Vossius C, Selbaek G, Ydstebø AE, Saltyte Benth J, Godager G, Lurås H, Bergh S. Ressursbruk og sykdomsforløp ved demens (REDIC) langversjon. In. Helse Sør-Øst: Alderpsykiatrisk forskningssenter, Sykehuset Innlandet; 2015.

32. Say J-B. A treatise on political economy. 6th ed. Philadelphia: Grigg \& Elliot; 1834.

33. Lystrup LS, Lillesveen B, Nygard AM, Engedal K. Public social health services to demented persons living at home in Norway. Tidsskrift for den Norske laegeforening : tidsskrift for praktisk medicin, ny raekke. 2006;126(15):1917-20.

34. Bremer P, Challis D, Hallberg IR, Leino-Kilpi H, Saks K, Vellas B, Zwakhalen SMG, Sauerland D. Informal and formal care: Substitutes or complements in care for people with dementia? Empirical evidence for 8 European countries. Health Policy (Amsterdam, Netherlands). 2017;121(6):613-22.

35. Bokberg C, Ahlstrom G, Leino-Kilpi H, Soto-Martin ME, Cabrera E, Verbeek H, Saks K, Stephan A, Sutcliffe C, Karlsson S. Care and Service at Home for persons with dementia in Europe. J Nurs Scholarsh. 2015;47(5):407-16.

36. Stephan A, Bieber A, Hopper L, Joyce R, Irving K, Zanetti O, Portolani E, Kerpershoek L, Verhey F, de Vugt M, et al. Barriers and facilitators to the access to and use of formal dementia care: findings of a focus group study with people with dementia, informal carers and health and social care professionals in eight European countries. BMC Geriatr. 2018;18(1):131.

37. Brodaty H, Thomson C, Thompson C, Fine M. Why caregivers of people with dementia and memory loss don't use services. Int I Geriatr Psychiatr. 2005; 20(6):537-46.

38. Macleod A, Tatangelo G, McCabe M, You E. "there isn't an easy way of finding the help that's available." barriers and facilitators of service use among dementia family caregivers: a qualitative study. Int Psychogeriatr. 2017;29(5):765-76.

39. Ward-Griffin C, Hall J, Deforge R, St-Amant O, McWilliam C, Oudshoorn A, Forbes D, Klosek M. Dementia home care resources: how are we managing? J Aging Res. 2012;2012:590724.

40. Mittelman MS, Haley WE, Clay OJ, Roth DL. Improving caregiver well-being delays nursing home placement of patients with Alzheimer disease. Neurology. 2006;67(9):1592-9.

41. Eldholm RS, Barca ML, Persson K, Knapskog AB, Kersten H, Engedal K, Selbaek G, Braekhus A, Skovlund E, Saltvedt I. Progression of Alzheimer's disease: a longitudinal study in Norwegian memory clinics. J Alzheimers Dis. 2018;61(3):1221-32.

42. Cortes F, Nourhashemi F, Guerin O, Cantet C, Gillette-Guyonnet S, Andrieu S, Ousset PJ, Vellas B. Prognosis of Alzheimer's disease today: a two-year prospective study in 686 patients from the REAL-FR study. Alzheimers Dement. 2008:4(1):22-9.

43. Leoutsakos JM, Han D, Mielke MM, Forrester SN, Tschanz JT, Corcoran CD, Green RC, Norton MC, Welsh-Bohmer KA, Lyketsos CG. Effects of general medical health on Alzheimer's progression: the Cache County dementia progression study. Int Psychogeriatr. 2012;24(10):1561-70.

\section{Publisher's Note}

Springer Nature remains neutral with regard to jurisdictional claims in published maps and institutional affiliations. 